\title{
CARACTERIZAÇÃo gUÍMICA E FÍsICA DE BATATAS ÁGATA E MONALISA MINIMAMENTE PROCESSADAS ${ }^{1}$
}

\author{
Lívia L. O. PINELI ${ }^{2, *}$, Celso L. MORETTI ${ }^{3}$, Gustavo C. ALMEIDA ${ }^{4}$, \\ Josiana Z. SANTOS ${ }^{3}$, Ana C. A. ONUKI ${ }^{5}$, Aline B. G.NASCIMENTO ${ }^{5}$
}

\begin{abstract}
RESUMO
O objetivo deste trabalho foi caracterizar química e fisicamente batatas minimamente processadas durante o armazenamento refrigerado. Batatas (Solanum tuberosum, L.) ágata e monalisa foram minimamente processadas como minibatatas. Após o processamento, as batatas foram acondicionadas sob vácuo parcial e, posteriormente, armazenadas em câmaras frias a 5 e $15^{\circ} \mathrm{C}$, por nove dias. A cada três dias, foram avaliadas as seguintes variáveis: firmeza, atividade da polifenoloxidase e peroxidase, açúcares solúveis totais, amido e vitamina C total. Nas batatas armazenadas a $15^{\circ} \mathrm{C}$, constatou-se que, após nove dias de armazenamento, sua firmeza era 3,3 vezes menor em batatas monalisa e 4,3 vezes menor para a cultivar ágata, quando comparadas com o produto recém-processado. A atividade da polifenoloxidase mostrou-se praticamente estável em batatas monalisa armazenadas a $5^{\circ} \mathrm{C}$. Batatas monalisa minimamente processadas apresentaram maior atividade da peroxidase a $5^{\circ} \mathrm{C}$, sendo $86 \%$ maior do que a atividade desta enzima em batatas ágata ao final do período experimental. O teor inicial de açúcares solúveis totais nas batatas minimamente processadas era $28 \%$ maior na cultivar monalisa, quando comparada com tubérculos de ágata. As duas cultivares apresentaram tendência de elevação do teor de amido nos primeiros três dias, para as duas temperaturas estudadas. Em ambas as cultivares, armazenamento a $5^{\circ} \mathrm{C}$ possibilitou maior manutenção dos teores de vitamina C.

Palavras-chave: enzimas, processamento mínimo, peroxidase, polifenoloxidase, amido, açúcar.
\end{abstract}

\section{SUMMARY}

CHEMICAL AND PHYSICAL CHARACTERIZATION OF FRESH-CUT POTATOES. The present work was carried out aiming to evaluate chemical and physical characteristics of fresh-cut potatoes stored under 5 and $15^{\circ} \mathrm{C}$. Potatoes, (Solanum tuberosum L.) ágata and Monalisa were minimally processed as baby potatoes. After processing, the material was packed under partial vacuum and stored at 5 and $15^{\circ} \mathrm{C}$ for nine days. Every three days tubers were evaluated for firmness, enzymatic activity (polyphenoloxidase and peroxidase), total soluble sugars, starch, and total vitamin C. After nine days of storage, monalisa and ágata potatoes stored under $15^{\circ} \mathrm{C}$ had a firmness that was 3.3 and 4.3 times lower than the same product right after processing. Polyphenoloxidase activity was approximately stable during the storage period for monalisa potatoes stored under $5^{\circ} \mathrm{C}$. Fresh-cut monalisa potatoes had the highest peroxidase activity at $5^{\circ} \mathrm{C}$, being $86 \%$ higher than ágata potatoes at nine days of storage. For total soluble sugars, monalisa potatoes had $28 \%$ more sugars than ágata right after processing. Both cultivars showed a tendency to increase starch content on the first three days of storage, for both temperatures studied. For both cultivars, it was verified that storage at $5^{\circ} \mathrm{C}$ allowed higher retention of total vitamin $\mathrm{C}$ content.

Keywords: enzymes, minimal processing, peroxidase, polyphenoloxidase, starch, sugars.

\section{1 - INTRODUÇÃO}

A batata (Solanum tuberosum L.), quarto alimento mais consumido no mundo, é considerada um dos dez principais produtos agrícolas brasileiros e a hortaliça mais importante para a economia nacional, representando faturamento superior a R\$ 1,4 bilhão [27]. Apesar da incontestável importância da cadeia da batata para o agronegócio brasileiro, a industrialização desta hortaliça é ainda incipiente em nível nacional, dando margem a um grande volume de importações do produto processado. O processamento mínimo tem sido uma das alternativas para agregar valor à batata brasileira e reduzir a importação do produto congelado.

\footnotetext{
${ }^{1}$ Recebido para publicação em 10/2/2005. Aceito para publicação em 23/1/2006 (001480)

${ }^{2}$ Programa de mestrado do Departamento de Nutrição. Universidade de Brasília (UnB)

CEP 70910-900 - Brasília (DF)

${ }^{3}$ Laboratório de Pós-colheita. Embrapa Hortaliças

CEP 70359-970 - Brasília (DF)

${ }^{4}$ Departamento de Ciência dos Alimentos. Universidade Federal de Lavras (Ufla)

CEP 37200-000 - Lavras (MG)

${ }^{5}$ Faculdade da Terra de Brasília

CEP 72610-300 - Brasília (DF)

E-mail: liviapineli@yahoo.com.br

*A quem a correspondência deve ser enviada
}

Produtos minimamente processados podem ser definidos como frutas ou hortaliças, ou combinação destas, que tenham sido fisicamente alterados, mas que permaneçam no estado fresco [26]. No Brasil, a comercialização de batatas minimamente processadas ainda é incipiente. Atualmente, o produto pode ser encontrado na forma palito, embalado sob vácuo parcial, nas gôndolas de alguns supermercados. O maior problema encontrado neste tipo de produto é o "encharcamento" das embalagens e perda intensa da firmeza, provavelmente devido ao uso de cultivares com teores muito baixos de matéria seca predominantes na produção nacional e às temperaturas das gôndolas refrigeradas insuficientemente (em torno de $15^{\circ} \mathrm{C}$ ) para a manutenção das características dos produtos [37].

Apesar desses problemas, a tendência é a expansão do segmento, considerando-se o consumo per capita de batata no País de 14,3 kg/hab ${ }^{-1} / \mathrm{ano}^{-1}$ [19], aliada à sua importância na dieta brasileira e à comodidade e o frescor oferecidos pelos produtos minimamente processados. Outro fator favorável a essa expansão é o menor custo de implantação de unidades de processamento mínimo de batatas para fritura ou para cocção, quando comparado com o das unidades agroindustriais para produção de batatas pré-fritas congeladas [6]. Todavia, um possível entrave para a expansão do processamento mínimo de batatas refere-se a sua produção em escala, visto que o País consome mais de 80 mil ton de batatas pré-fritas conge- 
ladas, o que exigiria investimentos significativos em plantas de processamento mínimo de batatas [35].

Batatas minimamente processadas destinadas à fritura devem utilizar matéria-prima com teor de sólidos solúveis superior a $20 \%$ e teor de açúcares redutores menor do que 3\% [6]. Esses atributos resultam em batatas fritas mais crocantes, secas e com menor ocorrência de escurecimento não-enzimático durante o aquecimento. Por outro lado, o processamento mínimo de batatas que se destinam à cocção não apresenta necessidades tecnológicas específicas, podendo-se utilizar qualquer cultivar para essa finalidade. Entretanto, os aspectos econômicos e de oferta ao longo do ano devem ser relevantes na escolha da matéria-prima.

No Brasil, atualmente, predomina a cultivar monalisa. A cultivar ágata é considerada promissora, em função da sua tuberização precoce, uniformidade e boa aparência dos seus tubérculos, atributo muito exigido pelos consumidores, e já se apresenta como a variedade de mais rápido crescimento em importância na bataticultura brasileira, ocupando, hoje, a segunda posição em área e produção [33]. Ambas são cultivares apropriadas para cocção, em virtude do seu baixo teor de matéria seca.

O processamento mínimo de batatas oferece, ainda, a possibilidade de se agregar valor às classificações de batatas que apresentam deságio por qualquer inadequação aos atributos de qualidade desejados pelo consumidor, mas que não comprometem a qualidade do tubérculo para fins culinários e industriais, como o caso das batatas com classificação "primeirinha" e "diversas".

Um dos grandes desafios ao processamento mínimo de batatas é a significativa susceptibilidade dos tubérculos ao escurecimento, oriundo de reações catalisadas por enzimas, sendo a mais importante a polifenoloxidase (PPO). As etapas de descascamento, corte ou fatiamento promovem o rompimento das estruturas celulares, permitindo o contato entre a enzima e os substratos fenólicos que podem resultar na formação de compostos escuros [3]. A enzima peroxidase (POD), também responsável pelo escurecimento em hortaliças minimamente processadas, está relacionada com processos de cicatrização [8, 30]. ROBINSON [46] revisou as funções fisiológicas da POD na pós-colheita de frutas e hortaliças e atribuiu a ela muitas das funções oxidativas de fenóis, inclusive a síntese de lignina e suberina para reconstituição de tecidos vegetais lesionados. A POD promove a oxidação de compostos fenólicos na presença de peróxido de hidrogênio [14], apresentando possível ação sinergística com a PPO [49].

Outras alterações decorrentes do processamento mínimo em batatas estão relacionadas com o aumento da atividade metabólica e com a descompartimentação de enzimas e substratos, podendo resultar em perda de firmeza, desenvolvimento de aromas e sabores desagradáveis (off-flavors) [21, 52, 47] e alterações dos teores de compostos nutricionais, como a vitamina $\mathrm{C} \mathrm{e}$ os compostos fenólicos [51, 11, 20, 41]. Para controle das reações degradativas e manutenção da qualidade do produto, o uso de refrigeração e a aplicação de atmosferas modificadas com reduzida concentração de oxigênio têm apresentado resultados promissores. A escolha da cultivar tem demonstrado efeito no potencial de escurecimento de batatas minimamente processadas, devido à diferença na composição química entre os cultivares de batata. AHVENAINEN \& HURME [1], ao estudarem várias cultivares de oito hortaliças (incluindo as batatas), concluíram que nem todas as cultivares de batatas podem ser utilizadas para o processamento.

Apesar da importância da batata para o a agronegócio brasileiro, existe uma lacuna na literatura consultada no que diz respeito à avaliação de materiais nacionais com potencialidade de uso na forma minimamente processada.

O objetivo deste trabalho foi caracterizar química e fisicamente batatas minimamente processadas, durante o armazenamento refrigerado.

\section{2 - MATERIAL E MÉTODOS}

\section{1 - Material vegetal}

Batatas (Solanum tuberosum L.) das cultivares monalisa e ágata, classificação "primeirinha"; adquiridas na Ceasa de Brasília e levadas ao Laboratório de Pós-colheita da Embrapa Hortaliças para: seleção, classificação e lavagem em água potável.

\section{2 - Processamento mínimo}

Em seguida, os tubérculos foram descascados por abrasão em máquina processadora (modelo PCED, Siemsem Ltda.), por $180 \mathrm{~s}$ em tambor revestido com lixa de 60 mesh, e $36 \mathrm{~s}$ no segundo tambor revestido com lixa de 100 mesh. Batatas descascadas foram enxaguadas em água potável, sanitizadas em água clorada ( 150 ppm de cloro ativo) por 5 min e centrifugadas por $10 \mathrm{~min}$ a $800 \mathrm{~g}$.

\section{3 - Embalagem e armazenamento}

O material foi posteriormente acondicionado por nylon multicamadas sob vácuo parcial (Seladora Selovac 200B, São Paulo (SP)), em porções de 200 g, e finalmente, armazenado sob refrigeração a 5 e $15^{\circ} \mathrm{C}$ por nove dias.

\section{4 - Análises químicas e físicas}

A cada três dias os tubérculos minimamente processados foram avaliados quanto às seguintes variáveis.

\subsection{1 - Firmeza}

Determinada pelo método da aplanação, descrito por CALBO e NERY [7].

\subsection{2 - Açúcares solúveis totais}

Determinados pelo método fenol-sulfúrico descrito por DUBOIS et al. [13]. 


\subsection{3 - Atividade enzimática da polifenoloxidase e peroxidase}

A atividade das enzimas foi determinada segundo o método descrito por FLURKEY \& JEN [17], sendo o extrato lido a $395 \mathrm{~nm}$ para POP e a $470 \mathrm{~nm}$ para POD.

\subsection{4 - Teor de amido}

Determinação feita a partir de adaptação realizada no método de RANGANNA [45], com extração de açúcares por solução de etanol (80\%) a quente, em três estágios; hidrólise ácida do resíduo, também em três estágios, com ácido perclórico (52\%), com posterior determinação dos açúcares pelo método fenol-sulfúrico.

\subsection{5 - Teor de vitamina $C$ total}

A vitamina $\mathrm{C}$ total foi quantificada de acordo com metodologia descrita por TERADA et al. [50], modificado por NUNES et al. [40].

\section{5 - Análise estatística}

O experimento foi conduzido em delineamento inteiramente casualizado, com 16 tratamentos arranjados em esquema fatorial $2 \times 2 \times 4$ ( 2 cultivares, 2 temperaturas e 4 tempos de amostragem), com três repetições. Os dados foram submetidos à análise de variância e as médias foram comparadas pelo teste de diferença mínima significativa $(\mathrm{P} \leq 0,05)$.

\section{3 - RESULTADOS E DISCUSSÃo}

\section{1 - Firmeza}

A perda de firmeza das batatas minimamente processadas foi observada em ambas as cultivares e temperaturas avaliadas, sendo mais severa naquelas submetidas ao armazenamento a $15^{\circ} \mathrm{C}$ (Figura 1 ).

Na temperatura de $15^{\circ} \mathrm{C}$, verificou-se que, após nove

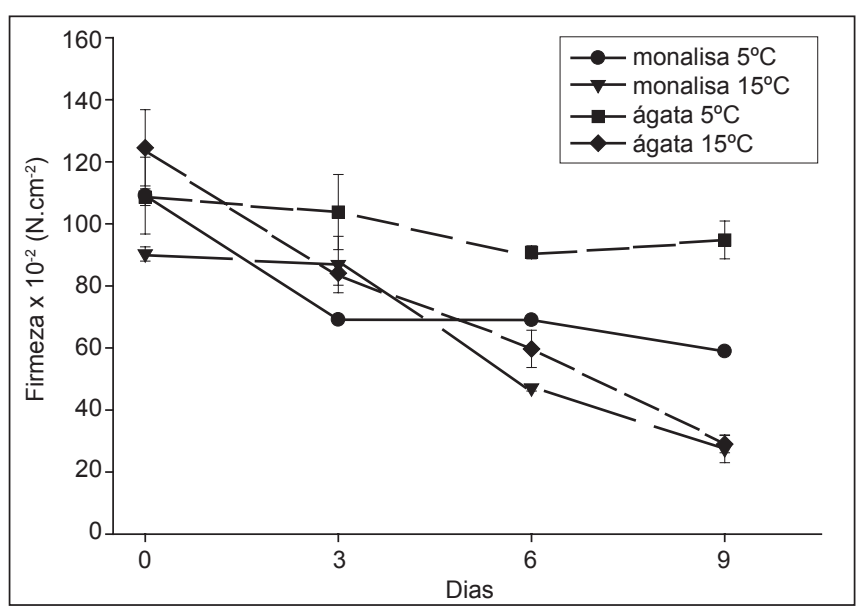

FIGURA 1 - Firmeza em batatas ágata e monalisa minimamente processadas e armazenadas a 5 e $15{ }^{\circ} \mathrm{C}$. Barras verticais representam o desvio padrão da média. Embrapa Hortaliças, Brasília (DF), 2004 dias de armazenamento, a firmeza era 3,3 vezes menor em batatas monalisa e 4,3 vezes menor para a cultivar ágata, quando comparadas com o produto recém-processado. Tal redução significativa possibilitou que batatas ágata, mais firmes inicialmente, atingissem firmeza muito próxima à da monalisa no último dia de avaliação.

Batatas ágata, armazenadas a $5^{\circ} \mathrm{C}$, apresentaram a maior firmeza, possuindo valores $50,6 \%$ superiores aos das batatas monalisa no terceiro dia de avaliação, à mesma temperatura. Tal tendência manteve-se constante durante o período experimental, sendo que ao final do intervalo de armazenamento, a firmeza das batatas ágata atingiu valores $53,2 \%$ superiores aos das batatas monalisa sob as mesmas condições de temperatura de armazenamento, ou seja, $5^{\circ} \mathrm{C}$ (Figura 1).

Diversos trabalhos têm demonstrado a possibilidade de o processamento mínimo de hortaliças causar várias alterações físicas, tais como a redução da firmeza do produto processado [47, 53]. Tal redução, que ocorre durante o armazenamento de frutas e hortaliças minimamente processadas, pode ter como uma das causas os processos metabólicos associados ao amadurecimento e à senescência, ou ainda, à perda de água. $\mathrm{O}$ amadurecimento e a senescência estão correlacionados com mudanças na atividade enzimática da parede celular [24, 16], alterações no $\mathrm{pH}$ e nos teores de agentes quelantes [32], resultando em mudanças na textura e amaciamento de polpa, desestruturação celular e aumento da presença de exsudados celulares. NOURIAN et al. [39], ao avaliarem a firmeza das batatas intactas, armazenadas sob diferentes temperaturas por 140 dias, observaram que temperaturas entre 4 e $8^{\circ} \mathrm{C}$ retardaram a perda de firmeza, favorecendo a manutenção da qualidade dos tubérculos por 133 dias; ao passo que, batatas armazenadas a 16 e $20^{\circ} \mathrm{C}$ apresentaram rápida depreciação na qualidade e textura, deteriorando-se em 21 e 35 dias, respectivamente.

Aliada à baixa temperatura, a manutenção da firmeza do produto pode ser conseguida com a aplicação, por imersão, de soluções de cálcio. LUNA-GUZMAN et al. [31] verificaram que melóes minimamente processados mergulhados por um minuto em soluções de $\mathrm{CaCl}_{2}(2 \%)$ a 20,40 e $60^{\circ} \mathrm{C}$, mantiveram ou melhoraram a firmeza do tecido, durante o armazenamento a $5^{\circ} \mathrm{C}$.

\section{2 - Atividade da polifenoloxidase e peroxidase}

A atividade da polifenoloxidase apresentou significativa elevação para batatas ágata, armazenadas a 5 e $15^{\circ} \mathrm{C}$ (Figura 2a).

As batatas minimamente processadas, da cultivar monalisa, apresentaram, comparativamente à ágata, menor incremento da atividade da polifenoloxidase após o processamento mínimo para ambas as temperaturas de armazenamento estudadas. Isso pressupõe que, possivelmente, a cultivar monalisa responde de maneira mais branda, ao estresse mecânico sofrido durante o processamento. No terceiro dia de observação verificou-se que a atividade da 


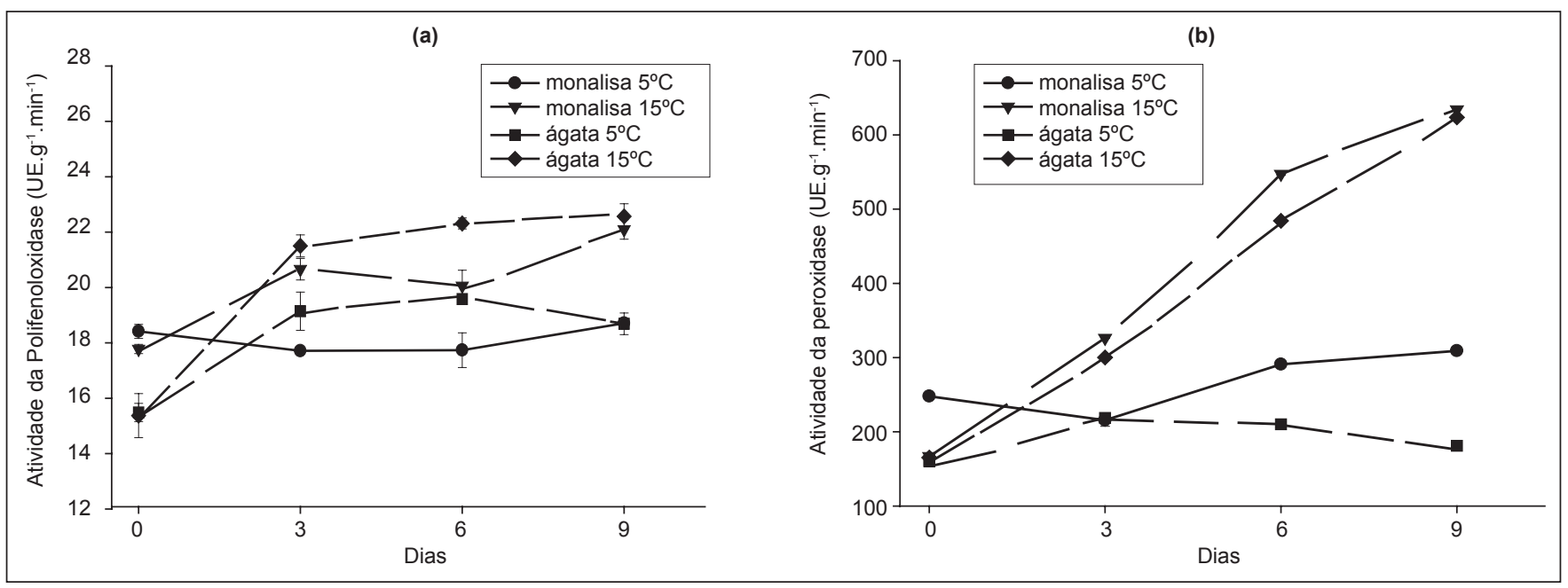

FIGURA 2 - Atividade da polifenoloxidase (a) e peroxidase (b) em batatas ágata e monalisa minimamente processadas e armazenadas a 5 e $15{ }^{\circ} \mathrm{C}$. Barras verticais representam \pm o desvio padrão da média. Embrapa Hortaliças, Brasília (DF), 2004

polifenoloxidase em batatas armazenadas a $15^{\circ} \mathrm{C}$ era $24 \mathrm{e}$ $46 \%$ maior para monalisa e ágata, respectivamente, quando comparadas com a atividade dessa enzima no tecido recém processado (Figura 2a).

Quando se avaliou a atividade da enzima peroxidase em batatas armazenadas a $5^{\circ} \mathrm{C}$, verificou-se que tubérculos da cultivar monalisa apresentaram maior atividade, representando valores de 48 e $86 \%$ superiores aos da atividade desta enzima nas batatas ágata, logo após o processamento mínimo e aos nove dias de armazenamento, respectivamente. Por outro lado, constatou-se que, batatas minimamente processadas e armazenadas a $15^{\circ} \mathrm{C}$, apresentaram aumento da atividade da peroxidase em cerca de quatro vezes para ambas as cultivares ao longo do período de armazenamento, quando comparado ao valor da atividade logo após o processamento e ao final do experimento (Figura $2 b$ ).

CANTOS et al. [8] avaliaram o efeito do processamento mínimo sobre a atividade das enzimas polifenoloxidase, peroxidase e fenilalanina amônia liase e nos compostos fenólicos, em cinco cultivares de batatas, e não encontraram correlação significativa entre o grau ou taxa de escurecimento e quaisquer das variáveis investigadas. Entretanto, o aumento da atividade da peroxidase, verificada pela síntese de isoperoxidases identificadas por eletroforese, confirmou a indução da atividade desta enzima como fenômeno comum no reino vegetal em resposta a situações de estresse, como injúrias mecânicas. Semelhante ausência de correlação foi encontrada entre grau de escurecimento e atividade enzimática de maçãs, durante o armazenamento a $0^{\circ} \mathrm{C}[10]$.

CANTOS et al. [8] estudaram também, nos mesmos materiais anteriormente relatados, a ocorrência de escurecimento. Verificaram que batatas monalisa foram consideradas as mais susceptíveis ao escurecimento, com grau máximo alcançado dois dias após o corte. Os autores não recomendaram a utilização desta cultivar para o processamento mínimo, em vista de seu potencial de escurecimento.

\section{3 - Açúcares solúveis totais e amido}

O teor inicial de açúcares totais em batatas minimamente processadas da cultivar monalisa era, em média, $28 \%$ maior em comparação ao da cultivar ágata (Figura 3).

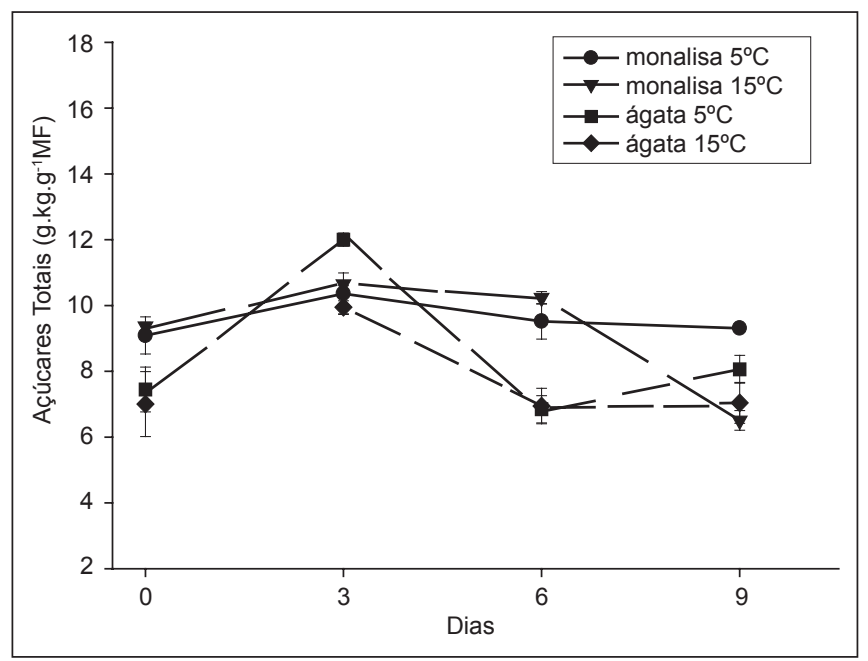

FIGURA 3 - Teor de açúcares solúveis totais em batatas ágata e monalisa minimamente processadas e armazenadas a 5 e $15{ }^{\circ} \mathrm{C}$. Barras verticais representam \pm o desvio padrão da média. Embrapa Hortaliças, Brasília (DF), 2004

Batatas monalisa, armazenadas a $15^{\circ} \mathrm{C}$, apresentaram pouca variação no teor de açúcares nos seis primeiros dias de armazenamento, com posterior decréscimo ao final do período de avaliação. Para batatas ágata, inicialmente com teor médio de 7,2 g. $\mathrm{kg}^{-1} \mathrm{MF}$ para ambas as temperaturas de armazenamento, foi verificado pico no teor de açúcares totais após três dias de armazenamento, com elevação dos teores desses carboidratos de $61,2 \%$ e $42 \%$ a 5 e $15^{\circ} \mathrm{C}$, respectivamente. Do sexto ao nono dia, observaram-se valores estatisticamente semelhantes aos iniciais, em ambas as temperaturas estudadas. 
Ao final do período de armazenamento, verificou-se também que as duas cultivares possuíam maior teor de açúcares solúveis totais em tubérculos armazenados a $5^{\circ} \mathrm{C}$ do que nos armazenados a $15^{\circ} \mathrm{C}$ (Figura 3). Tal fato indica a possível conversão do amido em açúcares solúveis totais, seguindo rotas metabólicas diversas, conforme discussão a seguir.

O teor inicial de amido verificado nas batatas minimamente processadas de todos os tratamentos situava-se entre 121 e 126 g. kg-1 MF (Figura 4).

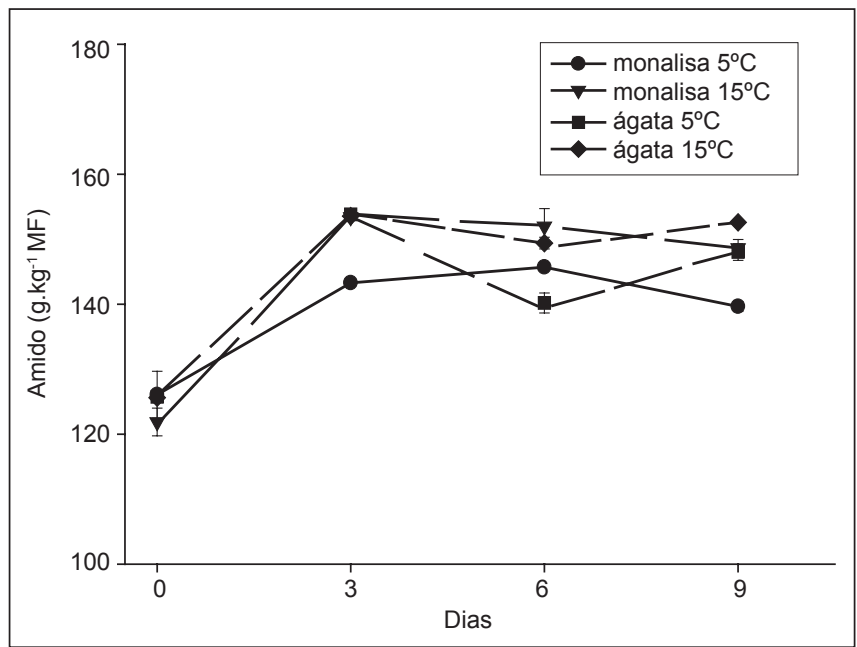

FIGURA 4 - Teor de amido em batatas ágata e monalisa minimamente processadas e armazenadas a 5 e $15^{\circ} \mathrm{C}$. Barras verticais representam \pm o desvio padrão da média. Embrapa Hortaliças, Brasília (DF), 2004

Os valores de amido, determinados no presente estudo, para os tubérculos das cultivares ágata e monalisa, logo após o processamento mínimo, se encontravam dentro da faixa reportada por BORGSTROM [5], que observou variação nos teores de amido na matéria fresca de batata de 90 a 180 g. $\mathrm{kg}^{-1} \mathrm{MF}$. Segundo o autor, a amplitude verificada é devido às diferenças genéticas entre cultivares, épocas de plantio, temperatura e tempo de armazenamento, dentre outros fatores [39, 23].

Em estudo com batatas armazenadas sob diferentes temperaturas, NOURIAN et al. [39] verificaram que a degradação do amido ocorreu mais rapidamente à temperatura mais baixa $\left(4^{\circ} \mathrm{C}\right)$, caindo de 134 para 80 g. $\mathrm{kg}^{-1} \mathrm{MF}$ em 35 dias, e para 63 g. $\mathrm{kg}^{-1} \mathrm{MF}$ em 133 dias. Por outro lado, constataram que os açúcares solúveis totais aumentaram de 12,4 para 18 e 34,8 g. $\mathrm{kg}^{-1}$ MF para os mesmos períodos de armazenamento estudados, respectivamente. Os autores verificaram também que o teor máximo de açúcares totais obtidos a $20^{\circ} \mathrm{C}$ em 35 dias foi de 13,5 g. $\mathrm{kg}^{-1} \mathrm{MF}$. Concluíram que a estocagem de batatas a baixas temperaturas levou ao maior acúmulo de açúcares a partir do amido, podendo promover alterações na cor pelo escurecimento não-enzimático, quando as mesmas forem submetidas a algum processamento térmico [9].

As condições de armazenamento à baixa temperatura propiciam o acúmulo de ATP no tecido da batata, acarretando a ativação de via metabólica alternativa, conhecida como res- piração resistente ao cianeto, levando à diminuição dos níveis de ATP e, simultaneamente, ao aumento das concentrações de sacarose, provavelmente via ação da enzima fosforilase [28, 4]. A sacarose torna-se então o substrato da invertase ácida vacuolar, que originará o acúmulo de açúcares redutores [15]. A indução do acúmulo de açúcares pelo frio estaria, ainda, relacionada com a deterioração das membranas dos amiloplastos [42] favorecendo a ação da enzima amidofosforilase sobre o amido [18], que tem como função biológica o aumento da tolerância a baixas temperaturas, agindo como crioprotetores [22].

Por outro lado, a atividade da sacarose sintetase, importante enzima envolvida na síntese do amido, é maior em tubérculos jovens de batata [44] nos quais se incluem, fisiologicamente, os tubérculos da classificação "primeirinha", usados no presente estudo. Tal fato explicaria, em parte, o aumento verificado nos teores de amido das duas cultivares estudadas nos três primeiros dias de armazenamento.

Apesar da conversão de amido em açúcares ser, aparentemente, reversível [12, 28], o aumento nos teores de amido encontrados no presente trabalho (Figura 4), parece estar relacionado tanto à maior atividade dos tubérculos jovens, quanto à perda de água sofrida pelos tubérculos após o processamento mínimo. Isso pode ser constatado pela elevação da umidade superficial do produto após a centrifugação e nos três primeiros dias de armazenamento, sendo que as batatas armazenadas a $15^{\circ} \mathrm{C}$ exsudaram mais água. A maior perda de água das batatas ágata minimamente processadas, observada visualmente, pode estar relacionada com o maior teor deste componente em sua composição centesimal (88\%), comparado com a cultivar monalisa (85\%). Do terceiro ao nono dia verificaram-se reduções entre 2,6 e $4 \%$ nos teores de amido, exceção feita à cultivar ágata armazenada a $5^{\circ} \mathrm{C}$, na qual constatou-se redução no sexto dia com posterior elevação dos teores de amido.

\section{4 - Vitamina $\mathbf{C}$ total}

As duas cultivares estudadas apresentaram tendência de redução dos teores de vitamina $\mathrm{C}$ total durante os seis primeiros dias de armazenamento, com posterior aumento nos teores dessa vitamina até o final do experimento (Figura 5).

Os valores de vitamina $\mathrm{C}$ total determinados no presente estudo, logo após o processamento mínimo, se encontravam dentro da faixa reportada por DAVEY et al. [11], que constataram que batatas apresentaram teores de vitamina C entre 100 e 300 mg. kg ${ }^{-1}$ MF. Segundo esses autores, tais valores variam em função das diferenças genéticas entre as cultivares, práticas agrícolas, colheita e condições de estocagem.

A cultivar ágata minimamente processada apresentou redução no teor de vitamina $\mathrm{C}$ de 52,5 e 39,6\% quando armazenada a $15^{\circ} \mathrm{C}$ e a $5^{\circ} \mathrm{C}$, respectivamente, até o sexto dia de armazenamento. A partir desse ponto, verificou-se que o teor da vitamina aumentou significativamente até o nono dia de armazenamento, atingindo 443,8 mg. $\mathrm{kg}^{-1} \mathrm{MF}$ para batatas a $5^{\circ} \mathrm{C}$ e $310,1 \mathrm{mg} \cdot \mathrm{kg}^{-1} \mathrm{MF}$ para tubérculos armazenados a $15^{\circ} \mathrm{C}$ (Figura 5). 


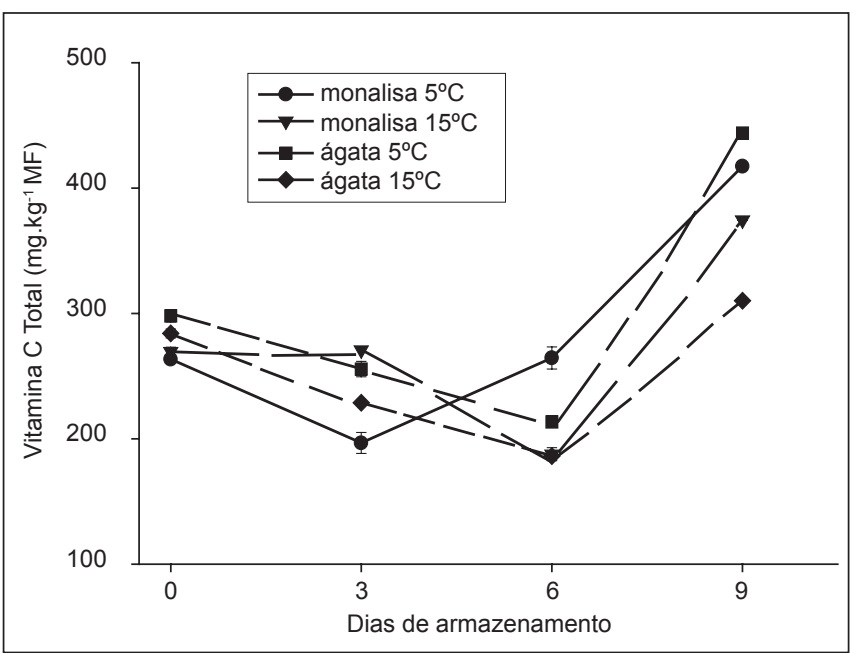

FIGURA 5 - Teor de vitamina $\mathrm{C}$ total em batatas ágata e monalisa minimamente processadas e armazenadas a 5 e $15^{\circ} \mathrm{C}$. Barras verticais representam \pm o desvio padrão da média. Embrapa Hortaliças, Brasília (DF), 2004

O decréscimo seguido de aumento na vitamina $\mathrm{C}$ foi verificado também para a cultivar monalisa, que, ao final do experimento, apresentava teores de 417,1 e 374,4 mg. $\mathrm{kg}^{-1}$ $\mathrm{MF}$ quando armazenada a 5 e $15^{\circ} \mathrm{C}$, respectivamente. Salienta-se que, para ambas as cultivares, o armazenamento a $5^{\circ} \mathrm{C}$ propiciou maior retenção dos teores de vitamina $\mathrm{C}$, demonstrando a eficiência da refrigeração para manutenção dos teores dessa vitamina.

Batatas minimamente processadas são capazes de reter seu teor inicial de vitamina $\mathrm{C}$ total ou parcialmente, uma vez que as perdas decorrentes de processos de oxidação são compensadas pelo aumento na biossíntese de ácido ascórbico [51, 34, 2, 48]. Esse aumento pode estar correlacionado com a maior atividade da enzima L-galactono- $\gamma$-lactona dehidrogenase (GLDH) em tecidos de batata injuriados [41], que catalisa o passo final da biossíntese do ácido ascórbico [36, 41$]$.

O aumento na biossíntese desse ácido orgânico poderia ser o resultado da maior necessidade de poder antioxidante, em nível celular, para fazer frente ao estresse provocado pelo processamento mínimo [25, 52]. Além disso, o aumento da atividade respiratória provocado pelo processamento mínimo leva à degradação do amido, com acúmulo de glicose, substrato requerido no processo de síntese de ascorbato [38]. Como visto anteriormente, o acúmulo de açúcares é maior à temperatura de $5^{\circ} \mathrm{C}$, o que explicaria em parte, a maior retenção de vitamina $\mathrm{C}$ total em batatas minimamente processadas armazenadas sob essa temperatura.

$\mathrm{Na}$ avaliação do teor de vitamina $\mathrm{C}$ em alimentos, deve-se ter ciência da existência de equilíbrio dinâmico entre as formas ácido ascórbico e deidroascórbico, sendo que esta é facilmente convertida na primeira no organismo humano. Na ocorrência de processos degradativos, o ácido deidroascórbico é oxidado irreversivelmente a ácido dicetogulônico, que não possui qualquer atividade de vita- mina C [43], redundando, em termos práticos, na perda de valor nutricional.

A oxidação do ascorbato pela ascorbato oxidase aumenta em condições de estresse, exposição a patógenos, altas temperaturas, íons metálicos e agentes químicos [29]. Portanto, o teor de vitamina $\mathrm{C}$ em batatas minimamente processadas é resultante de processos biossintéticos e degradativos que ocorrem simultaneamente. No estudo apresentado, deve-se considerar a possibilidade da ocorrência de síntese de ascorbato em resposta ao estresse oxidativo, o que culminou com a elevação do teor de vitamina $\mathrm{C}$ ao final do período experimental.

TUDELA et al. [52] estudaram o efeito do processamento mínimo, com subseqüente armazenamento sob refrigeração a $4^{\circ} \mathrm{C}$, de batatas da cultivar manon, sob diferentes atmosferas (ar, ar $+20 \%$ de $\mathrm{CO}_{2}, 100 \% \mathrm{~N}_{2}$, e embalagem a vácuo), na atividade da enzima L-galactono- $\gamma$-lactona dehidrogenase e no teor de vitamina C. Esses pesquisadores verificaram que a embalagem a vácuo demonstrou ser a melhor opção, tendo evitado o escurecimento e retido $89 \%$ da vitamina $\mathrm{C}$, seguido da embalagem sob as atmosferas de $100 \% \mathrm{~N}_{2}$ (78\% de retenção de vitamina C) e $20 \% \mathrm{CO}_{2}+$ ar $(63 \%$ de retenção de vitamina $\mathrm{C}$ ).

\section{4 - CONCLUSÕES}

Batatas armazenadas a $5^{\circ} \mathrm{C}$ apresentaram melhor conservação, no que diz respeito à manutenção das características físicas e químicas durante o armazenamento. Visualmente, observou-se em embalagens a $5^{\circ} \mathrm{C}$, a ocorrência de escurecimento de forma pontual, localizada em regiões de enrugamento da embalagem pela ação do vácuo. As batatas de ambas as cultivares apresentaram aspecto satisfatório para comercialização até o sexto dia de armazenamento, o que está em conformidade com o prazo de validade normalmente observado para produtos minimamente processados.

Não se verificou grande diferença entre as variáveis analisadas quando se comparou as cultivares ágata e monalisa. Todavia, a menor susceptibilidade ao escurecimento enzimático da cultivar ágata em armazenamento a $5^{\circ} \mathrm{C}$ deve ser levada em consideração, uma vez que a cor é um ponto fundamental para a qualidade global do produto e aceitação pelo consumidor. Destaca-se a manutenção de níveis elevados de vitamina $\mathrm{C}$ no produto minimamente processado ao final do experimento, o que reforçaria os benefícios do consumo da batata como importante fonte deste nutriente.

\section{5 - REFERÊNCIAS BIBLIOGRÁFICAS}

[1] AHVENAINEN, R.; HURME, E. Minimal processed of vegetable. In: AHVENAINEN, R.; MATTILA-SANDHOLM, T.; OHLSSON, T. (ed) Minimal Processing of Foods, Espoo, VTT Symposium, 142 p., 1994.

[2] ASSELBERGS, E.A.M.; FRANCIS, F.J. Studies on the formation of vitamin $\mathrm{C}$ of potato tissue. Canadian Journal of Botanic, v. 30, p. 665, 1952. 
[3] ARAÚJO, J.M. Química de alimentos - teoria e prática, $3^{\text {a }}$ ed., Viçosa, Editora UFV, 2003.

[4] BARKER, J. Studies in the respiratory and carbohydrate metabolism in plant tissues. XXIV. The influence of a decrease in temperature on the content of certain phosphate esters in plant tissues. New Phytologist, v. 67, p. 487-493, 1968.

[5] BORGSTROM, G. Principles of Food Science $2^{\text {a }}$ ed., Connecticut, Food and Nutrition Press, 1946.

[6] BERBARI, S.A.G.; AGUIRRE, J.M. Alternativas para o aproveitamento de Batata. Batata Show, v. 2, n. 4, 2002.

[7] CALBO, A.G.; NERY, A.A. Medida de firmeza em hortaliças pela técnica de aplanação. Horticultura Brasileira, v. 3, n. 1, p. 14-18, 1995.

[8] CANTOS, E.; TUDELA, J.A.; GIL, M.I.; ESPÍN, J.C. Phenolic compounds and related enzymes are not rate-limiting in browning development of fresh-cut potatoes. Journal of Agric. and Food Chemistry, v. 50, p. 3.015-3.023, 2002.

[9] COELHO, A.H.R; VILELA, E.R; CHAGAS, S.J.R. Qualidade de batata (Solanum tuberosum L.) para fritura, em função dos níveis de açúcares redutores e de amido, durante o armazenamento refrigerado e à temperatura ambiente com atmosfera modificada. Ciência e Agrotec. Lavras, v. 23, n. 4, p. 900-911, 1999.

[10] COSETENG, M.Y., LEE, C.Y. Changes in apple polyphenoloxidase and polyphenol concentrations in relation to degree of browning. Journal of Food Science, v. 52, n. 4, p. 985-989, 1987.

[ 11 ] DAVEY, M.W.; MONTAGU, M.V.; INZÉ, D.; SANMARTIM, M.; KANELLIS, A.; SMIRNOFF, N.; BENZIE, I.J.J.; STRAIN, J.J.; FAVEL, D.; FLETCHER, J. Plant ascorbic acid: chemistry, function, metabolism, bioavailability and effects of processing. Journal of Science and Food Agriculture, v. 80, p. 825-860, 2000.

[12] DEITING, U.; ZRENNER, R.; STILL, M. Similar temperature requirement for sugar accumulation and for the induction of new forms of sucrose phosphate synthase and amylase in cold-stored potato tubers. Plant, Cell and Environment. v. 21, p. 127-138, 1998.

[13] DUBOIS, M.; GILLES, K.A.; HAMILTON, J.K.; REBERS, P.A. \& SMITH, F. Colorimetric method for determination of sugars and related substances. Anal. Chem. v. 28, p. 350-356, 1956.

[14] DUNDFORD, H.B.; STILLMAN, J.S. On the function and mechanism of action of peroxidases. Coord. Chem. Rev. v. 19, p. 187-251, 1976.

[15] DUPLESSIS, P.M.; MARANGONI, A.G.; YADA, R.Y.A Mechanism for low temperature induced sugar accumulation in stored potato tubers: the potential role of alternative pathway and invertase. American Potato Journal, v. 73, p. 97-100, 1996.

[16] FISCHER, R.L., BENNETT, A.B. Role of cell wall hydrolases in fruit ripening. Annu. Rev. Plant Physiol. Plant Molec. Biol. v. 42, p. 675-703, 1991.

[17] FLURKEY, W.H.; JEN, J. Peroxidase and polyphenoloxidase activities in developing peaches. Journal of Food Science, v. 43, p. 1.826-1.828, 1978.

[18] FONTES, P.C.R.; FINGER, F.L. Pós-colheita do tubérculo de batata. $1^{\text {a }}$ ed., Viçosa, Editora UFV, 2000.

[19] FOOD AND AGRICULTURE ORGANIZATION. Statistical databases. Food Supply 2001. Disponível em: $<$ http:// faostat.fao.org/faostat/collections?version=ext\&hasbul $\mathrm{k}=0 \&$ subset $=$ nutrition $>$ Acesso em 28 jul. 2004 .

[20] FUKUDA, M.; KUNISADA, Y.; NODA, H.; TAGAYA, S.; YAMAMOTO, Y.; KIDA, Y. Effect of storage time of potatoes after harvest on increase of ascorbic acid content by wounding. Journal of the Jpn. Soc. of Food Science and Technology, v. 42, n. 1.031-1.034, 1995.

[21] GUNES, G.; LEE, C.Y. Colour of minimally processed potatoes as affected by modified atmosphere and ant browning agents. Journal of Food Science, v. 62, p. 572-575 e 582, 1997.

[22] GUY, C.L. Cold acclimation and freezing stress tolerance: role of protein metabolism. Annual Review of Plant Physiology and Plant Molecular Biology, v. 41, p. 187-223, 1990.

[23] HERTOG, M. L. A.T.M; TUSKENS, L.M.M.; HAK, P.S. The effects of temperature and senescence on the accumulation of reducing sugars during storage of potato (Solanum tuberosum L.) tuber: a mathematical model. Postharvest Biology and Technology, v. 10, p. 67-69, 1997.

[24] HUBER, D.J. The role of cell wall hydrolases in fruit softening. Horticultural Review, v. 5, p. 169-219, 1983.

[25] IMAHORI, Y; YAN-FEI, Z; UEDA, Y; ABE, K; CAHCHIN, K. Effects of wound stress by slicing sweet pepper fruits on ascorbic acid metabolism. J. Jpn. Soc. Hortic. Sci., v. 66, p. 175-183, 1997.

[26] INTERNATIONAL FRESH CUT PRODUCE ASSOCIATION. About IFPA. Disponível em <http://www.freshcuts.org/>. Acesso em 23 abr. 2004.

[27] INSTITUTO BRASILEIRO DE GEOGRAFIA E ESTATÍSTICA. Sistema IBGE de recuperação automática. produção agrícola municipal 2002. Disponível em $<$ www.sidra.ibge. gov.dr/bda/acervo/acervo2 $\cdot \operatorname{asp} ? \mathrm{e}=\mathrm{v} \& \mathrm{p}=\mathrm{pa} \& \mathrm{z}=\mathrm{t} \& \mathrm{o}=11>$ Acesso em 16 jun. 2004.

[28] ISHERWOOD, F.A. Starch-sugar interconversion in Solanum tuberosum. Phytochemistry, v. 12, p. 2.579$2.591,1973$.

[29] LEE, S.K.; KADER, A.A. Preharvest and postharvest factors influencing vitamin $\mathrm{C}$ content of horticultural crops. Postharvest Biology and Technology, v. 20, p. 207-220, 2000.

[30] LÓPEZ-SERRANO, M.; RÓS-BARCELO, A. Activity of. peroxidase in unripe and processing strawberries. Food Chemistry, v. 52, p.157-160, 1995.

[31] LUNA-GUZMAN, I.; CANTWELL, M.; BARRETT, D.M. Fresh-cut cantaloupe: effects of $\mathrm{CaCl}_{2}$ dips and heat treatments on firmness and metabolic activity. Postharvest Biol. Technol., v. 17, p. 201-213, 1999.

[32] MACDOUGALL, A.J., PARKER, R; SELVENDRAN, R.R. Nonaqueous fractionation to assess the ionic composition of the apoplast during fruit ripening. Plant Physiol., v. 108, p. 1.679-1.689, 1995.

[33] MELO, P.C.T.; GRANJA, N.P; FILHO, H.S.M.; SUGAWARA, A.C.; OLIVEIRA, R.F. Análise do crescimento da cultivar de batata ágata. Batata Show, v. 3, n. 8, p. 16-17, 2003.

[34] MONDY, N.I.; LEJA, M. Effect of mechanical injury on the ascorbic acid content of potatoes. Journal of Food Science, v. 51, p. 355-359, 1986. 
[35] MORETTI, C.L. Processamento mínimo: uma alternativa de agregação de valor para a bataticultura brasileira. Batata Show, n. 9, p. 31-32, 2004.

[36] MUTSUDA, M.; ISHIKAWA, T.; TAKEDA, T.; SHIGEOKA, S. Subcellular localization and properties of L-galactono- $\Upsilon$-lactone dehidrogenase in spinach leaves. Bioscience, Biotechnology, and Biochemistry, v. 59, p. 1.983-1.984, 1995.

[37] NASCIMENTO, E.F., MORETTI, C.L., ZUCHETTO, M.C., MATTOS, L.M. Avaliação da temperatura de comercialização de hortaliças minimamente processadas no mercado varejista do Distrito Federal. In: Congresso Brasileiro de Olericultura, 43, 2003, Recife. Anais do Congresso Brasileiro de Olericultura. Recife: SOB, 2003. cd-rom.

[38] NOCTOR, G; FOYER, C.H. Ascorbate and gluathione: keeping active oxygen under control. Annu. Rev. Plant. Physiol. Mol. Biol., v. 49, p. 249-279, 1998.

[39] NOURIAN, F; RAMASWAMY, H.S; KUSHALAPPA, A.C. Kinetics of quality change associated with potatoes stored at different temperatures. Lebensm.-Wiss. U.Technol., v. 36, p. 49-65, 2003.

[40] NUNES, M.C.N.; BRECHT, J.K.; MORAIS, A.M.M.B.; SARGENT, S.A. Physical and chemical quality characteristics of strawberries after storage are reduced by a short delay to cooking. Postharvest Biology, v. 6, p. 17-28, 1995.

[41] OBA, K. FUKUI, M.; IMAI, Y.; IRYAMA, S.; NOGAMI, K. L-galactono- $\Upsilon$-lactone dehydrogenase: partial characterization, induction of activity and role in the synthesis of ascorbic acid in wounded white potato tuber tissue. Plant Cell. Physiology, v. 35, p. 473-478, 1994.

[42] OHAD, I.; FRIEDBERG, I.; NEMAN, Z.; SCRAMM, M. Biogenesis and degradation of starch. The fate of amyloplast membrane during maturation and storage of potato tubers. Plant Physiology, v. 47, p. 465-477, 1971.

[43] PARVIAINEN, M. T.; NYYSSONEM, K. Ascorbic Acid. In: LEENHEER, A.P.D; LAMBERT, W.E. NELIS, H. (Eds) Modern Chromatografic Annalysis of Vitamins., New York, Marcel Dekker Inc., 1992.

[44] PRESSEY, R. Role of invertase in accumulation of sugars in cold-stored potatoes. American Potato Journal, v. 46, p. 291-297, 1969.

[45] RANGANNA, S. Handbook of analysis and quality control for fruits and vegetables products. Tata Mcgraw Publishers, New Delhi, p. 106-107, 1986.

[46] ROBINSON, D.S. Peroxidases and catalases in foods.In Oxidative Enzymes in Foods, ed. ROBINSON, D.S.; ESKIN, N.A.M. Elsevier Applied Science, London, p. 147, 1991.

[47] ROLLE, R., CHISM, G.W., Physiological consequences of minimally processed fruits and vegetables. Journal of Food Quality, v. 43, p. 274-276, 1987.

[48] SMITH, O. Potatoes: production, storing, processing, $2^{\text {a }}$ ed., Westpot, Avi. Publishing, 1977.

[49] SUBRAMANIAN, N., VENKATESH, P.; GANGULI, S.; SINKAR, V.P. Role of poliphenol oxidase and peroxidase in the generation of black tea theaflavins. Journal of Agriculture and Food Chemistry, v. 47, p. 2.571-2.578, 1999.

[50] TERADA, M.; WATANABE, Y.; KUNITOMA, M.; HAYASHI, E. Differential rapid analysis ascorbic acid and ascorbic acid 2-sulfate by dinitrophenilhydrazine method. Annals of Biochemistry, v. 4, p. 604-608, 1979.

[51] TUDELA, J.A.; ESPÍN, J.C.; GIL, M.I. Vitamin C retention in fresh-cut potatoes. Post Harvest Biology and Technology, v. 26, p.75-84, 2002.

[52] TUDELA, J.A.; HERNÁNDEZ, J.A.; GIL, M.I.; ESPÍN, J.C. L-galactono- $\gamma$-lactone dehydrogenase activity and vitamin C content in fresh-cut potatoes stored under controlled atmospheres. Journal of Agric. and Food Chemistry, v. 51, p. 4.296-4.302, 2003.

[53] WATADA, A.E., ABE, K., YAMUCHI, N. Physiological activities of partially processed fruits and vegetables. Food Technology, v. 44, p. 116-122, 1990.

\section{6 - AGRADECIMENTOS}

Acordo Bird / Prodetab-Embrapa - Projeto 019, ADF Agropecuária e Ceasa - Brasília (DF). 